\title{
A paisagem natural e gestão territorial para Comunidade de Patrimônio da Penha, Caparaó - ES
}

\author{
Aline Oliveira Azevedo, Simone Neiva \\ Loures Gonçalves, Teresa da Silva Rosa*
}

\begin{abstract}
Resumo Durante a década de 1970, houve um aumento da preocupação da preservação ambiental ocasionada pela nova demanda das cidades. Assim, as problemáticas urbano-ambientais tornaram-se um enfrentamento das políticas públicas. Em contrapartida, houve um crescente aumento da criação de pequenos núcleos urbanos que buscam filosofias de vida voltadas à sustentabilidade do território em áreas que possuem uma paisagem natural ainda pouco modificada. Desse modo, o artigo faz um estudo de caso na Comunidade de Patrimônio da Penha, localizada no Município de Divino de São Lourenço - ES, onde os novos habitantes vêm influenciando o uso consciente dos recursos naturais da região.
\end{abstract}

Palavras-chave: unidade de conservação, preservação da paisagem, diretrizes projetuais.

\section{Paisaje natural y gestión territorial para la Comunidad del Patrimonio de Penha, Caparaó - ES}

Resumen Durante la década de 1970, ha habido un aumento de la preocupación de la preservación del medio ambiente causado por la nueva demanda de ciudades. Así, los problemas ambientales urbanos se convirtió en una confrontación de las políticas públicas. Por otra parte, hubo un aumento creciente en la creación de pequeños centros urbanos buscando filosofías de vida centrado en la sostenibilidad del territorio en áreas que tienen un paisaje natural todavía ligeramente modificado. Así, el artículo es un estudio de caso en la comunidad de la Penha de patrimonio, situado en el municipio de Divino de São Lourenço-ES, donde los habitantes han sido que influyen en el uso consciente y sostenible de los recursos naturales.

Palabras clave: unidad de conservación, preservación del paisaje, directrices proyectuales.

\section{Natural landscape and territorial mana- gement for the Community of Patrimony of Penha, Caparaó - ES}

\begin{abstract}
During the 1970s, there was an increase in the concern for environmental preservation caused by new demand from cities. Thus, the urban-environmental problematic has become a confrontation of public policies. On the other hand, there has been a growing increase in the creation of small urban centers that seek philosophies of life focused on the sustainability of the territory in areas that have a natural landscape that has not yet been modified. In this way, the article makes a case study in the Community of Patrimony of Penha, located in the Municipality of Divino de São Lourenço - ES, where the inhabitants have been influencing the sustainable and conscious use of natural resources.
\end{abstract}

Keywords: conservation unit, landscape preservation, design guideline. 
* Aline Oliveira Azevedo é Arquiteta e Urbanista, Professora de Arquitetura e Urbanismo da Faculdade Brasileira Multivix, ORCID <http://orcid.org/00000001-7701-8696>. Simone Neiva Loures Gonçalves é Arquiteta e Urbanista, Professora e pesquisadora dos Programas de Pós-Graduação e Graduação em Arquitetura e Urbanismo da Universidade de Vila Velha - ES, ORCID <http://orcid.org/0000-0003-3791-4888>. Teresa da Silva Rosa é Geógrafa, Professora e pesquisadora dos Programas de Pós Graduação em Sociologia Política e em Arquitetura e Cidade da Universidade Vila Velha-ES, ORCID <http://orcid.org/0000-0001-6613-5088>. fetivamente a partir da década de 1970, o modelo de "cidade moderna" começa a sofrer um enfraquecimento em razão das constantes revisões que desenho urbano vinha sofrendo. Lamas (2007) demonstra que "[...] esta rejeição à cidade moderna foi tão apaixonada e emotiva quanto fora anos antes a condenação da cidade tradicional e da rue corridor feita por Le Corbusier e pelos CIAM [...]" (LAMAS, p.28, 2007).

Todavia, em paralelo às problemáticas da emergência da cidade moderna houve um aumento da conscientização da preservação ambiental, tendo em vista que a crescente urbanização das cidades havia alcançado os limites das áreas de equilíbrio ambiental, causando a desconfiguração da paisagem natural. Com isso, muitas pessoas passaram a buscar um novo estilo de vida em pequenos núcleos urbanos, optando por um equilíbrio entre o espaço urbano e a natureza, afastando-se em parte das grandes cidades, buscando assim, princípios de vida que visam uma relação harmônica entre a natureza e o convívio com as pessoas (BESKOW; MATTEI, 2012).

Partindo dessa premissa, para o desenvolvimento deste artigo, optou-se pela escolha de Patrimônio da Penha, uma pequena comunidade inserida na zona de amortecimento de impacto do Parque Nacional do Caparaó e pertencente ao Município de Divino de São Lourenço - ES, localidade esta que tem atraído o interesse de pessoas para a região do Caparaó em razão da paisagem natural ainda pouco modificada. Dessa forma a propor uma agenda urbana voltada a preservação da paisagem e dinâmica natural, a fim de propor diretrizes que sejam capazes agregar aos documentos técnicos já existentes na preservação da paisagem e as características culturais que compõe o espaço territorial de Patrimônio da Penha.

A metodologia caracteriza-se como uma abordagem qualitativa, de natureza aplicada, com o objetivo exploratório em razão das sugestões de diretrizes projetuais para Patrimônio da Penha. Dessa forma, o método se divide em quatro etapas. A primeira - levantamento bibliográfico - constituiu na determinação dos conceitos básicos de bibliografias e a definição do ambiente contextualizador do problema. A segunda - diagnóstico da área de estudo - aproximação direta do território como área de pesquisa. A terceira etapa - aplicação de questionário - importante fase para compreender o olhar das pessoas sobre o lugar. a quarta etapa - elaboração de uma agenda urbana - que se restringiu à elaboração das propostas diretrizes projetuais atribuída aos princípios da agenda urbana para Patrimônio da Penha.

Com isso, como forma de minimizar os futuros impactos resultante das ocupações urbanas, as diretrizes projetuais propostas têm a intenção de contribuir como um instrumento norteador para a preservação da paisagem natural de Patrimônio da Penha, sobretudo, podendo servir como base para outras comunidades e/ou pequenos núcleos urbanos que possuam essas características. 


\section{Instrumentos de regulamentação ambiental para Unidades de Conservação}

Os instrumentos de regulamentação ambiental são ferramentas essenciais para auxílio da gestão e planejamento das UCs, sendo o Plano de Manejo o principal instrumento norteador para a implantação de uma área de preservação. O Ministério do Ambiente caracteriza o Plano de Manejo como sendo um documento:

"[...] elaborado a partir de diversos estudos, incluindo diagnósticos do meio físico, biológico e social. Ele estabelece as normas, restrições para o uso, ações a serem desenvolvidas e manejo dos recursos naturais da UC, seu entorno e, quando for o caso, os corredores ecológicos a ela associados, podendo também incluir a implantação de estruturas físicas dentro da UC, visando minimizar os impactos negativos sobre a UC, garantir a manutenção dos processos ecológicos e prevenir a simplificação dos sistemas naturais". (MINISTÉRIO DO MEIO AMBIENTE, 2018)

Outra ferramenta importante que vai complementar as vigências de uma Unidade de Conservação, será o Plano Diretor Municipal, já que essas áreas verdes estão inseridas normalmente dentro de um contexto urbano, gerando uma administração compartilhada das duas esferas, Federal e Municipal.

\section{Sistema Nacional de Unidades de Conservação}

O antigo Instituto Brasileiro de Desenvolvimento Florestal (IBDF) criado em 1967, integrou-se ao Ministério da Agricultura, e foi o primeiro órgão público a possuir atribuições voltadas a proteção das áreas verdes. Além disso, também foi também o pioneiro na elaboração de um planejamento de um Sistema de Unidade de Conservação no Brasil, a partir da regulamentação do Decreto Lei $n^{\circ} 289$, de 28 de fevereiro de 1967, que estabeleceu em seu Artigo $2^{\circ}$ :

"Art. $2^{\circ}$ - O IBDF destina-se a formular a política florestal bem como a orientar, coordenar e executar ou fazer executar as medidas necessárias à utilização racional, à proteção e à conservação dos recursos naturais renováveis e ao desenvolvimento florestal do País de conformidade com a legislação em vigor". (BRASIL, 1967)

A disposição de um Sistema de Unidade de Conservação no Brasil começou a mudar, a partir de 1976, com a elaboração de um documento denominado Uma análise de prioridades em conservação da natureza na Amazônia, o qual se tornou um instrumento de fundamentação do Plano do Sistema Nacional de Unidades de Conservação no Brasil, publicado em 1979 e 1982 (VILELA; BONFIM, 2014).

Ainda como forma de concentrar as questões ambientais em um conselho mais abrangente voltado a valorização do cenário ambiental, foi criado também em 1989, o Instituto Brasileiro do Meio Ambiente e dos Recursos Naturais Renováveis (IBAMA), que teve o intuito de "colocar pela primeira vez a política ambiental brasileira em geral, e a de UCs em particular, fora da esfera produtivista" (ROCHA, et al in SOUZA, p.94, 2016). 
1 É o entorno de uma unidade de conservação, onde as atividades humanas estão sujeitas a normas e restrições específicas, com o propósito de minimizar os impactos negativos sobre a unidade (MINISTÉRIO DO MEIO AMBIENTE, 2018)
Após um longo período de aproximadamente oito anos de tramitação no Congresso Nacional brasileiro, foi então sancionada em 18 de julho de 2000, a Lei n 9.985/2000, que instituiu o Sistema Nacional de Unidades de Conservação:

"Art. 1o Esta Lei institui o Sistema Nacional de Unidades de Conservação da Natureza - SNUC estabelece critérios e normas para a criação, implantação e gestão das unidades de conservação.

Art. $2^{\circ}$ Para os fins previstos nesta Lei, entende-se por:

I - Unidade de conservação: espaço territorial e seus recursos ambientais, incluindo as águas jurisdicionais, com características naturais relevantes, legalmente instituído pelo Poder Público, com objetivos de conservação e limites definidos, sob regime especial de administração, ao qual se aplicam garantias adequadas de proteção;

II - conservação da natureza: o manejo do uso humano da natureza, compreendendo a preservação, a manutenção, a utilização sustentável, a restauração e a recuperação do ambiente natural, para que possa produzir o maior benefício, em bases sustentáveis, às atuais gerações, mantendo seu potencial de satisfazer as necessidades e aspirações das gerações futuras, e garantindo a sobrevivência dos seres vivos em geral. Dentre outros incisos". (BRASIL, 2000).

Devido ao crescimento acelerado das cidades, as áreas limites às Unidades de Conservação começaram a ser ocupadas. O manejo inadequado nessas proximidades passou a afetar a instabilidade ambiental da UC (ICMBio, 2009). Assim, cresce a importância de não apenas preservar os espaços de interesse ambiental, mas, também, seu entorno, pois este contribuirá para salvaguardar as áreas de equilíbrio ambiental, denominadas zonas de amortecimento ${ }^{1}$. O objetivo das áreas consideradas Zonas de Amortecimento de Impacto (ZAI) é "minimizar impactos e ordenar o uso e a ocupação das atividades antrópicas geradas na região do entorno da Floresta Nacional [...] de forma a diminuir suas consequências sobre a [Unidade de Conservação]» (ICMBio, p.17, 2009).

No artigo $2^{\circ}$, inciso XVIII Lei $n^{\circ} 9.985 / 2000$, considera a ZAI um raio de 10 quilômetros a partir dos limites das unidades de conservação que possuam Plano de Manejo (CHIMALLI, 2013). Com isso, o Conselho Nacional do Meio Ambiente - CONAMA,

"[...] passou a estabelecer normas relativas ao entorno das unidades de conservação, mencionando que num raio de $10 \mathrm{~km}$ qualquer atividade que afete a biota deverá obter licença ambiental, a qual só será concedida mediante a autorização do órgão ambiental responsável pela administração da unidade de conservação". (FERREIRA e PASCUCHI, 2009)

Com isso, as UCs no Brasil passaram a ser compreendidas como sendo um espaço territorial com características naturais relevantes. Devido ao seu potencial ecológico, muitos são os estudos realizados anualmente sobre essas unidades. Entretanto, a ausência de uma análise sistêmica dos resultados da utilização desse instrumento faz com que muitos dados contidos em plataformas sejam faltosos, desencadeando em uma fragmentação de informações. 


\section{Parque Nacional do Caparaó}

O Parque Nacional do Caparaó está situado entre os Estados de Minas Gerais e Espírito Santo (fig. 01) e possui atualmente uma extensão territorial de 31.762,93 hectares distribuídos em um relevo irregular com diversas ondulações (ICMBio, 2015).

Por se tratar de um reconhecimento ambiental consolidado pós ocupação urbana, os moradores do entorno do Parque não foram consultados quando se decretou essa porção do território uma área de preservação ambiental. Surge então as primeiras tensões existente no território.

"A criação de novos usos para o território, com a instituição de novas regras, muitas das quais anulando as já existentes, provocou de imediato reações adversas por parte de alguns moradores locais. Estes não entendiam as proibições colocadas pela imposição desses novos usos pela legislação, que passaram a interferir em suas práticas cotidianas, deflagrando ações de degradação contra a área e as estruturas que já haviam sido implantadas ali". (SOUZA, p.116, 2016)

\section{Plano de Manejo do Parque Nacional do Caparaó}

O plano de manejo é definido pelo Ministério do Meio Ambiente, como sendo:

"Documento técnico mediante o qual, com fundamento nos objetivos gerais de uma unidade de conservação, se estabelece o seu zoneamento e as normas que devem presidir o uso da área e o manejo dos recursos naturais, inclusive a implantação das estruturas físicas necessárias à gestão da unidade". (ICMBio, p.08 e 09, 2009)

O Art. 27 da Lei Federal $n^{\circ}$ 9.985, de 18 de julho de 2000, determina ainda que o Plano de Manejo, "deve abranger a área da unidade de conservação, sua zona de amortecimento e os corredores ecológicos, incluindo medidas a fim de promover integração com a vida econômica e social das comunidades vizinhas" (ICMBio, p. 21 , 2009). Para a implementação de um Plano de Manejo, primeiramente deve haver um reconhecimento das características determinantes da área a ser considerada uma Unidade de Conservação:

"[...] conhecer o ecossistema, os processos naturais e as interferências antrópicas positivas e negativas que os influenciam ou os definem, considerando o uso que o homem faz do território, analisando os aspectos pretéritos e os impactos atuais ou futuros de forma a elaborar meios para conciliar o uso dos espaços com os objetivos de criação da Unidade de Conservação". (ICMBio, 2018)

Ainda que o Plano de Manejo, não seja o único instrumento regulamentador de uma UC, este é considerado de grande importância no que tange os interesses e as vigências da área de preservação. Mas, para que haja uma resposta satisfatória quanto à preservação é necessário a participação da população durante as revisões desse instrumento e as comunidades estabelecida nesta região para que assim sejam elaboradas as vigências em comum acordo aos interesses da UC e da população do entorno. 


\section{Plano Diretor Municipal}

O Plano Diretor Municipal (PDM) tem como finalidade instrumental respeitar os interesses sociais, garantindo a população o direito ao espaço urbano de qualidade, além de definir o Poder Público como mentor na atuação da gestão da cidade, oferecendo aos habitantes a oportunidade de atuação conjunta na tomada de decisões para uma melhor condição da organização das cidades e qualidade de vida aos cidadãos (DORNELAS, 2011).

Embora seja um instrumento complexo que irá estabelecer escopo para o regimento municipal, a cada cinco anos o plano diretor deve ser passado por revisões que irão fazer adaptações às novas exigências comunitárias. Assim, se torna um documento de uso contínuo que irá atender e ordenar o crescimento e das demandas da cidade em prol dos benefícios da sociedade.

Ao analisarmos as propostas estabelecidas nos princípios fundamentais para política territorial no PDM de Divino de São Loureço vigente (2008), nos deparamos com "promoção da sustentabilidade". Entretanto, esse termo não se estende as questões que tange a sustentabilidade ambiental do espaço, uma vez que parte esse território municipal estar inserido dentro de uma Reserva Biológica Natural, do Parque Nacional do Caparaó e o mesmo não destaca está área verde em seu PDM.

No PDM de Divido de São Lourenço é possível perceber que boa parte das atribuições deste instrumento é aplicado de maneira abrangente a todo município inclusive estendendo-se a Comunidade de Patrimônio da Penha que possui características específicas por estar inserida dentro de uma zona de amortecimento do Parque Nacional do Caparaó onde existem limitações quanto ao uso do solo, e mesmo assim, são poucas as ponderações existentes para essa área no PDM deste Município.

Embora o PDM tenha como objetivo a garantia do bem-estar coletivo a partir de um ordenamento territorial, em muitos casos a administração pública trata este documento técnico de maneira geral, focando mais as atribuições a sede municipal, sendo que cada parte desse território possui características diversificadas e que exigem um olhar individual na elaboração de seus instrumentos legais.

\footnotetext{
2 As formas urbanas não têm apenas a ver com as concepções estéticas, ideológicas, culturais ou arquitetônicas, mas encontramse indissociavelmente ligadas a comportamentos, à apropriação e utilização do espaço, e à vida comunitária dos cidadãos (LAMAS, p. 28, 2007).
}

\section{A Comunidade de Patrimônio da Penha enquanto território}

Segundo Lamas (2007), o território é "[...] a extensão da superfície terrestre na qual vive um grupo humano, ou melhor, o espaço construído pelo homem. [...] É o espaço onde o homem exerce sua acção [...]" (LAMAS, p.63, 2007). Desse modo, a geografia do espaço vai determinar a forma urbana² do território a ser criado a partir das interferências ocorridas pelo homem.

O território é o palco onde as ações do homem vão ser expostas, reconhecemos também que a diversidade entre os atores, os grupos sociais, uso da paisagem e as apropriações do solo vão ser fundamentais para dar contorno à geografia humanística na região. Desse modo o espaço ocupado "[...] se transforma em lugar quando adquirisse definição, valor e significado para o grupo humano que o ocupa, gerando assim, uma identificação e uma sensação de pertencimento" (SANTOS p.119, 2014). 
Mapa 1: Mapa de localização de Patrimônio da Penha. Fonte: Geobases (2018). Adaptado pelo autor e elaborador.
Por se tratar de um organismo vivo, as cidades sofrem constantemente modificações e novas adaptações, isso ocorre em razão da função física do espaço e da diversidade cultural que habita determinado região, a cidade se torna o reflexo da população.

Patrimônio da Penha possui uma localização estratégica no que se refere à paisagem natural, pois está situada a aproximadamente um quilometro dos limites do Parque Nacional do Caparaó (Mapa 1). Este pequeno núcleo urbano possui aproximadamente quinhentos habitantes, segundo informações contidas no cadastro dos agentes de saúde municipal, distribuídos em uma extensão territorial de 216.961,50 m².

Com a aprovação da Lei 9.985/2000, já mencionado anteriormente, Patrimônio da Penha passa estar inserida dentro da zona de amortecimento de impacto do Parque Nacional do Caparaó, com isso, o território passa a ter a necessidade de dialogar com o seu uso do solo com o Plano de Manejo desta Unidade de Conservação.

Embora a Comunidade de Patrimônio da Penha (Figura 1) já possuísse uma pequena ocupação anteriormente, foi somente a partir de 1980, com a chegada dos primeiros forasteiros vindos de diversas regiões do país que Patrimônio da Penha começou a ter seu reconhecimento paisagístico e cultural. Estes novos habitantes vieram atraídos pelas paisagens, pois, buscavam uma nova alternativa de vida em harmonia entre 0 espaço e a natureza (MASSINI, et al, 2015).

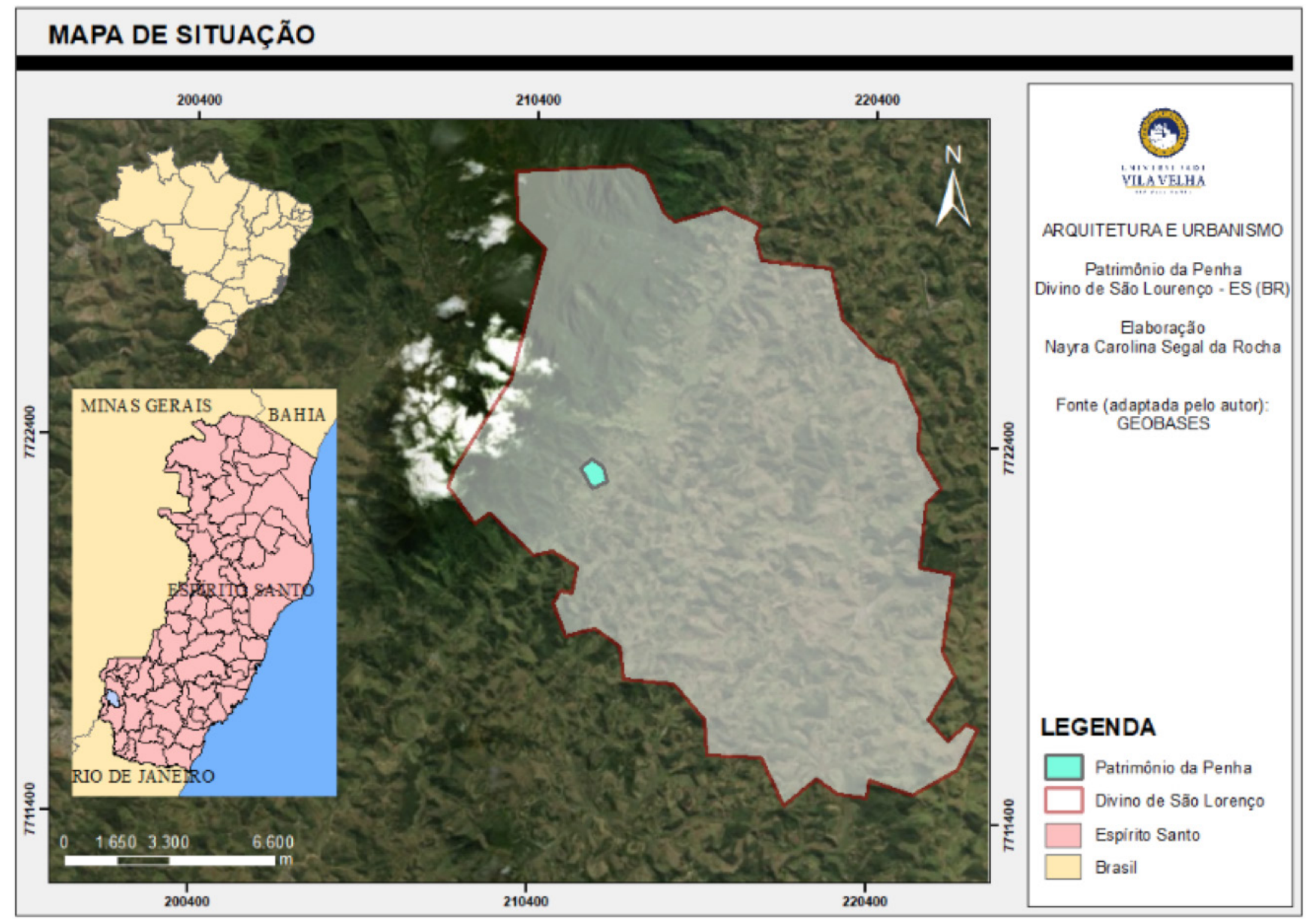




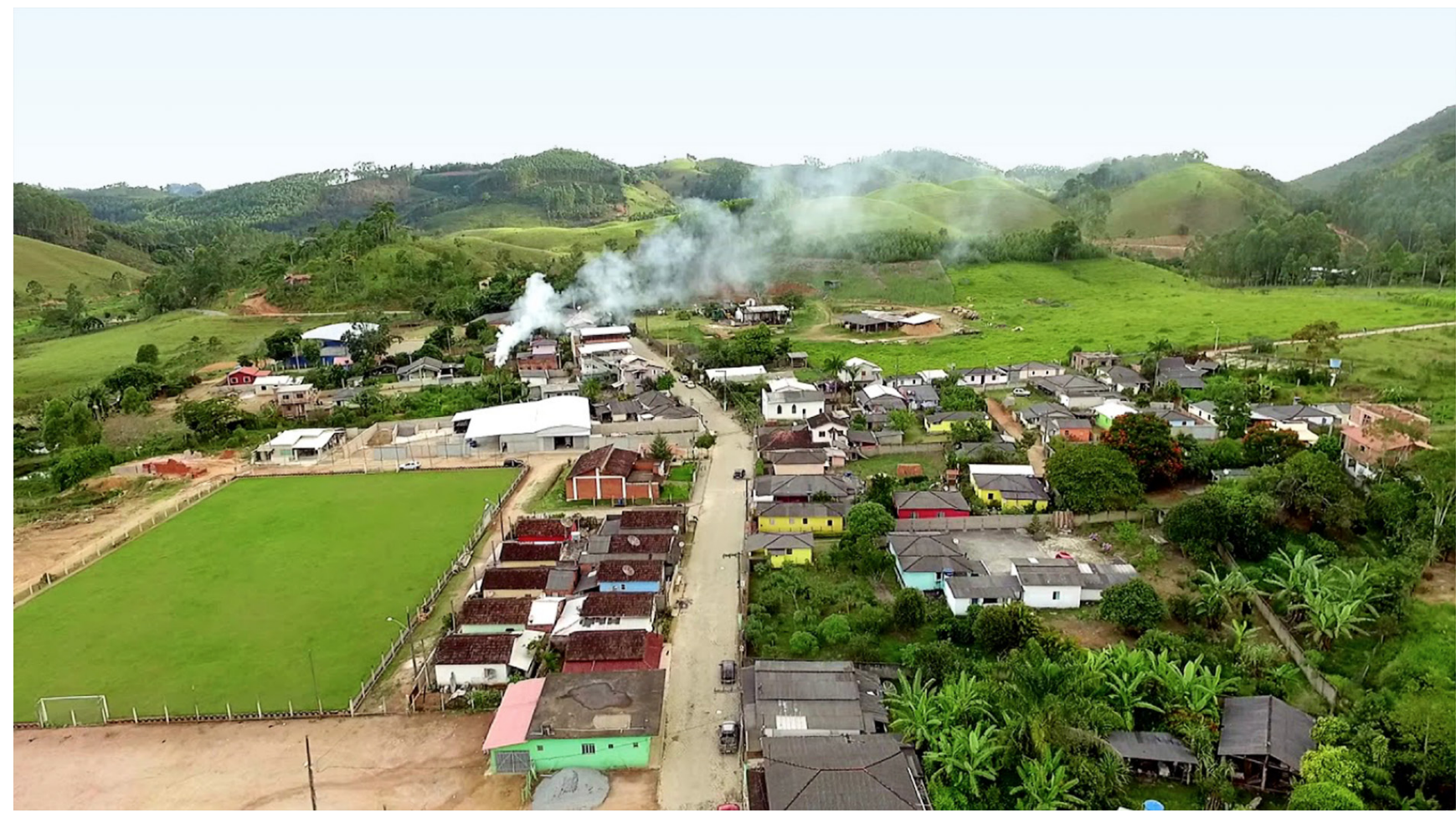

Figura 1: Patrimônio da Penha - ES. Fonte: Marco Venicio Freire (2017).
Com o aumento da chegada dos novos moradores com culturas e filosofias diferente tem possibilitado a existência de algumas desavenças, principalmente ao que diz respeito ao aumento do uso de drogas dentro da Comunidade e até mesmo quanto algumas festas temáticas que ocorrem durante ao ano. Entretanto há aqueles que também concordam que a vinda desses novos povos, agregou cultura a Patrimônio da Penha, principalmente no que diz respeito a preservação da mata e das cachoeiras, muitos aprovam o cuidado que os "alternativos" tem com o espaço.

Assim, atualmente a Comunidade de Patrimônio da Penha tem sido palco de atuação de três principais atores: os moradores nativos, os alternativos e o poder público. Entretanto, devido à omissão de um posicionamento do poder público municipal, este ficou à mercê de quaisquer esclarecimentos sobre a atuação na Comunidade de Patrimônio da Penha.

Entretanto, as diferentes percepções voltadas ao uso espaço, fez com que o modelo de vida estabelecido pelos alternativos agregasse à cultura enraizada dos moradores locais, o que possibilitou, sobretudo, a soma de suas diferentes visões sobre o território. Além do mais as condutas adotadas pelos alternativos tem se tornado um espelho cultural para a Comunidade de Patrimônio de Penha, criando para o local uma nova identidade a partir da busca pela sustentabilidade urbana, preservação da paisagem e a conservação dos seus recursos naturais. 


\section{A paisagem natural e os recursos ambientais de Patrimônio da Penha}

Ao discutirmos as questões ambientais devemos partir do princípio de identificação das características geomorfológicas de determinado sítio, é nesse momento que a infraestrutura da paisagem se torna importante. Mascaró (2008) vai então definir a paisagem como:

"[...] um espaço aberto que se abrange com um só olhar [...] uma realidade ecológica, materializada fisicamente num espaço que se poderia chamar natural (se considerado antes de qualquer intervenção humana), no qual se inscrevem os elementos e as estruturas construídas pelo homem". (MASCARÓ, p. 15, 2008)

No caso de Patrimônio da Penha, a paisagem natural passou a ser vista também como parte integrante da cultura adotada pela nova sociedade local. É a partir dela que tem havido a promoção do bem-estar coletivo e a boa relação do homem com a natureza, pois este passou a compreender a importância da preservação do lugar, além de ter impulsionado o incentivo ao turismo ecológico na região.

Entretanto, não se pode deixar de destacar nesse contexto a direta influência que o Parque Nacional do Caparaó para a preservação ambiental dessa porção do território, pois são devido às legislações estabelecidas pelo plano de manejo que tem assegurado os resquícios de mata nativa. Outro fator ocorre em razão do circuito do Caparaó que possibilita a passagem de diversos turistas pela Comunidade de Patrimônio da Penha.

Por estar situada dentro de uma ZAI de uma UC, em Patrimônio da Penha podemos perceber o reflexo dessa diversidade paisagística, principalmente o que diz respeito aos recursos disponíveis no parque que se estende até a localidade que possibilita a criação um corredor verde nesse território.

Devido ao fato de Patrimônio da Penha estar situado em uma área de elevada altitude de aproximadamente 690 metros juntamente com a aproximação com o Parque Nacional do Caparaó, possibilitou a preservação de uma considerável parte seus recursos naturais.

Atualmente Patrimônio da Penha se tornou um importante circuito turístico da região do sul, e isso se deu em razão de sua singularidade ambiental e a nova cultura que tem disseminado na Comunidade. Devido a isso o lugarejo se tornou dinâmico a partir das atividades disponíveis diariamente pela população. Hoje quem visita a Comunidade, tem a possibilidade de fazer trilhas pela mata, usufruir de cachoeiras, além das programações encontradas dentro da parte urbana da cidade.

\section{A morfologia urbana do território de Patrimônio da Penha - ES}

O termo morfologia é utilizado segundo Lamas (2007) "para designar o estudo da configuração e da estrutura exterior de um objeto. É a ciência que vai estudar as formas integrando-as com os fenômenos que lhes deram origem" [...] dessa forma "a morfologia urbana estudará essencialmente os aspectos exteriores do meio urbano e as suas relações recíprocas, definindo e explicando a paisagem urbana e a sua estrutura" (LAMAS, p. 37, 2007). 
3 Conjunto de objectos arquitetônicos ligados entre si por relações espaciais (LAMAS, p. 38, 2007).

Mapa 2: Elementos morfológicos do espaço urbano a luz de Lamas (2007). Fonte: Geobases (2018), adaptado pelo autor e elaborador.
A morfologia urbana engloba em seus levantamentos uma diversidade de áreas de conhecimentos além da arquitetura, são utilizados como estudos econômicos, históricos, geográficos, sociais dentre outros para contribuir para o conhecimento da forma urbana ${ }^{3}$ de determinado território.

Os critérios utilizados para definir os elementos morfológicos do espaço urbano foram baseados na literatura de Lamas (2007) (Mapa 2). A seguir serão apresentados os resultados dos mapeamentos da Comunidade de Patrimônio da Penha a partir da morfologia urbana do território. Para isso foram analisadas e levantadas um total de 194 edificações que se encontram dentro do perímetro urbano da Comunidade.

Sendo assim, a morfologia urbana do território contribui para que o desenho urbano além de atender as necessidades de organização do espaço e das atividades, este vai proporcionar a relação entre a estética e significado de determinada localidade. Com isso "o campo de estudo da morfologia será então a totalidade do território como lugar de transformações produzidas pelo homem, ou, por outras palavras, todo território como lugar de intervenção da arquitectura" (LAMAS, p. 70, 2007).

MAPA DE ELEMENTOS MORFOLÓGICOS DO ESPAÇO URBANO (LAMAS, 2007)

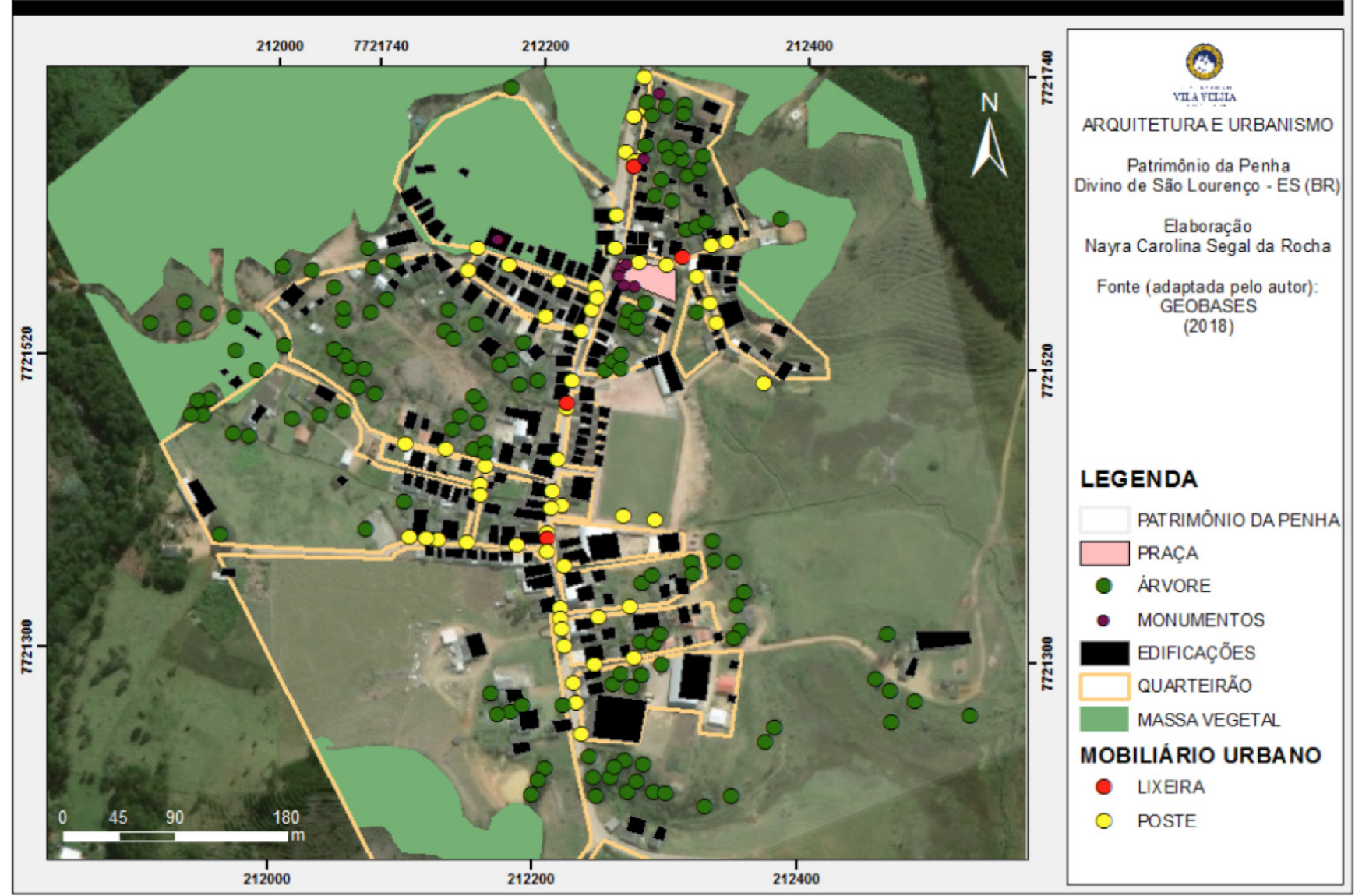


Mapa 3: Zoneamento territorial de Patrimônio da Penha - ES Fonte: Plano Diretor Municipal de Divino de São Lourenço (2008).

Tabela 1: Zoneamento de Patrimônio da Penha a luz do PDM vigente de Divino de São Lourenço. Fonte: Plano Diretor Municipal de Divino de São Lourenço (2008).

\section{Zoneamento}

Segundo Del Rio (1990), os zoneamentos "são os mais populares instrumentos para o controle do desenvolvimento urbano e provavelmente continuarão sendo" (DEL RIO, p. 108, 1990). É a partir desse instrumento que o município faz a organização e a setorização de seu território. A seguir o mapa de zoneamento territorial proposto pela Prefeitura Municipal de Divino de São Lourenço para a Comunidade de Patrimônio da Penha (Mapa 3).

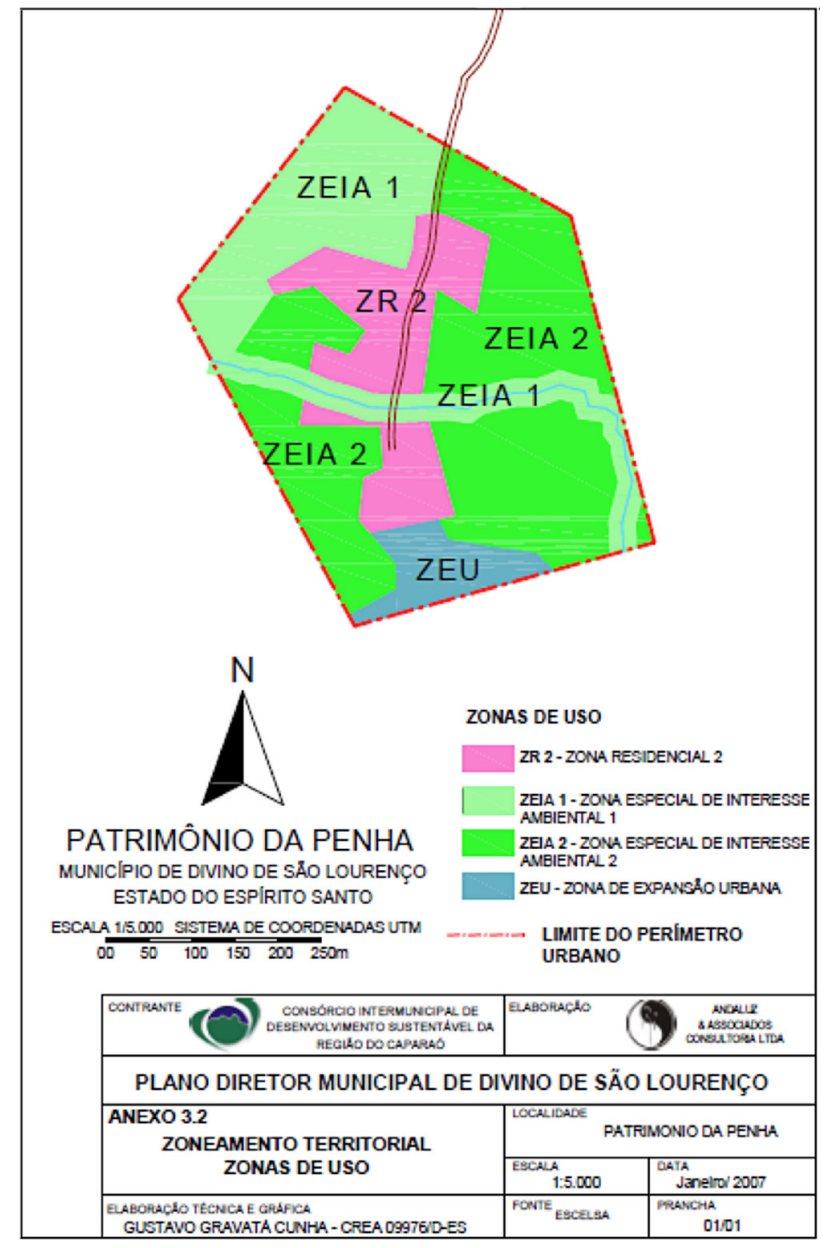

ZONEAMENTO

ZR 2 - Zona Residencial

ZEIA 1 - Zona

Especial de

Interesse Ambiental 1

ZEIA 2 - Zona

Especial de

Interesse

Ambiental 2

ZEU - Zona de Expansão Urbana

\section{DIRETRIZES}

É composta por áreas de uso predominantemente residencial com alguma concentração de comércio e de serviços de abrangência local.

Caracteriza-se, por seus aspectos físicos ou ambientais, como áreas non aedificandi e destinadas à preservação integral dos ecossistemas e dos recursos naturais, não envolvendo dano ou destruição dos mesmos, respeitando-se os usos e zoneamento estabelecidos em seus respectivos planos de manejo.

Caracterizam-se por seus aspectos físicos e ambientais, como áreas non aedificandi e destinadas à recuperação e conservação das características naturais e paisagísticas, onde o uso e ocupação do solo devem ser controlados de forma a assegurar a qualidade ambiental, podendo ser utilizada para fins rurais, de pesquisa científica, monitoramento e educação ambiental, recreação, realização de eventos culturais e esportivos e atividades de apoio ao turismo. Integram a ZEIA 2 as áreas com declividade acima de 30\%, sem vegetação natural passível de ocupação rural.

Composta por áreas ainda não parceladas reservadas à futura expansão urbana, próximas às áreas ocupadas. 
Mapa 4: Mapa de Uso e Ocupação do Solo. Patrimônio da Penha - ES. Fonte: Geobases (2018). Adaptado pelo autor e elaborador.

\section{Uso e Ocupação do Solo}

O que tange o uso do solo "trata-se de um instrumento de controle do desenvolvimento bastante inovativo, pois, baseia-se na ideia de separar o direito de construir do terreno onde fisicamente esse empreendimento se daria" (DEL RIO, p. 113, 1990). Entretanto, para Lamas "o solo-pavimento é um elemento de grande importância no espaço urbano, mas elemento também de grande fragilidade e sujeito a continuas mudanças" (LAMAS, p. 80, 2007).

O uso do solo vai "tratar basicamente de tipos de funções e intensidades de utilização do solo e das edificações; busca uma variedade e misturas de funções compatíveis entre si [...]" (DEL RIO, p. 107, 1990).

Para a elaboração do mapa de uso e ocupação do solo (Mapa 04) foram utilizados o modelo de ocupação do lote, distinguindo pelas categorias: residencial unifamiliar (apenas uma unidade habitacional por lote), residencial multifamiliar (quando ocorre mais de duas ocupações habitacionais dentro de um mesmo lote), comercial (destinados a comercialização e/ou armazenamento de produtos varejista ou atacado), serviços (atribuído a implantação de atividades que vão de encontro aos interesses da população) institucionais (são destinados as prática religiosa, pronto atendimento de saúde, escolas etc.) e por fim o uso misto (este modelo de ocupação é quando são exercidos no mesmo lote duas ou mais atividades distintas, tal como comercio e habitação).

\section{MAPA DE USO E OCUPAÇÃO DO SOLO}

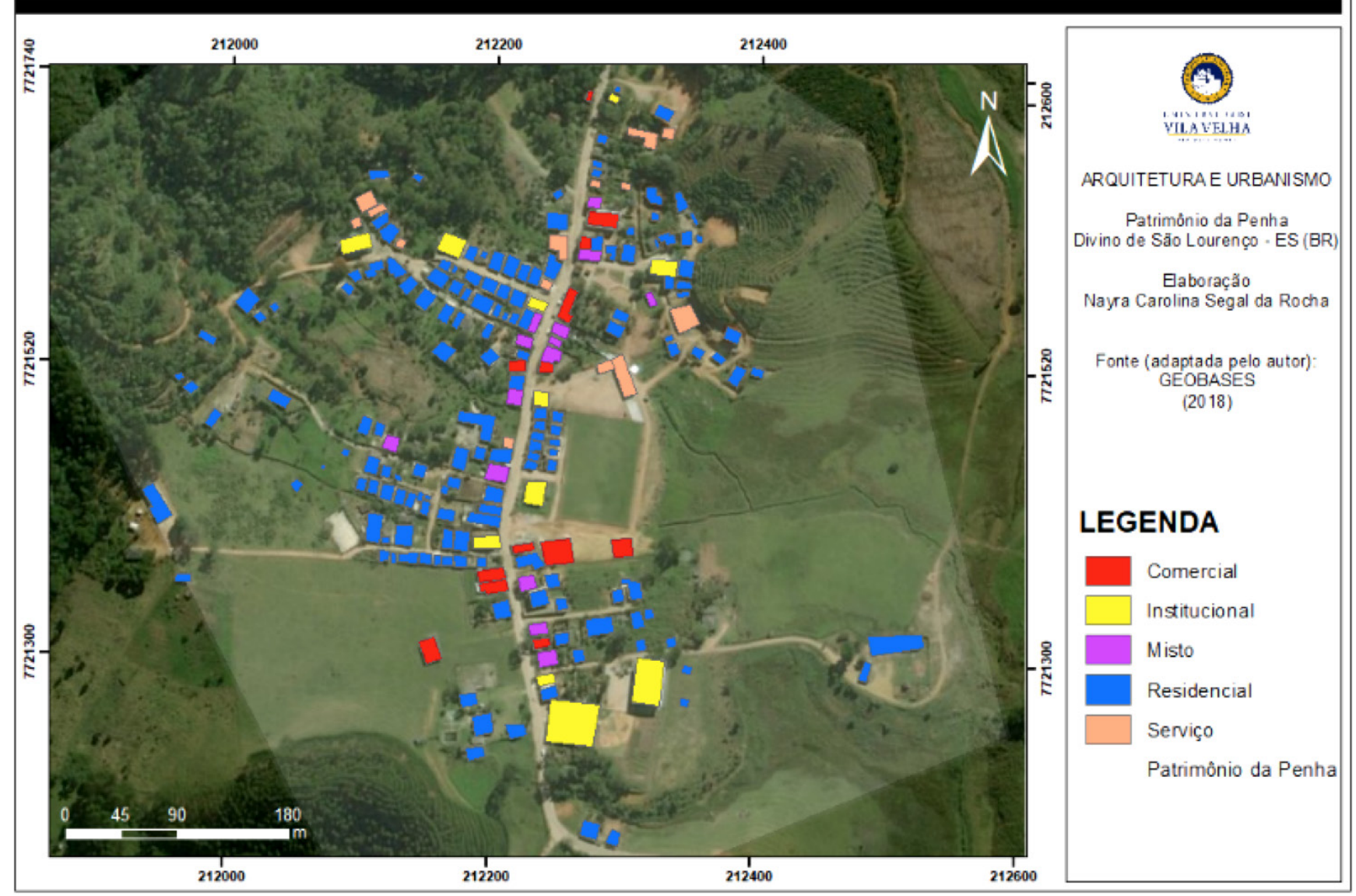


Tabela 2: Gabaritos permitidos para edificações a partir do zoneamento de Patrimônio da Penha. Fonte: Plano Diretor Municipal de Divino de São Lourenço (2008). Tabela elaborada pelo autor.

\section{Gabarito}

A análise do gabarito de um determinado local se torna importante para identificar a escala edificante com a escala humana da cidade e como estes se relacionam dentro do território. Segundo Jan Gehl (2013)

"[...] a comunicação entre edifícios altos e seus arredores é excelente a partir dos dois andares inferiores e possível a partir dos terceiros, quarto e quinto andar. Podemos, então, ver e acompanhar a vida da cidade; podemos perceber a fala, gritos e movimentos de braços. Estamos realmente participando da vida da cidade. Acima do quinto andar a vida muda drasticamente. Os detalhes não podem mais ser vistos, as pessoas no nível do solo não podem ser reconhecidas nem contatadas [...]". (GEHL, p. 42, 2013)

Neste caso, ao analisarmos o mapa a seguir percebe-se a predominância de gabaritos que vão de 1-3 pavimentos na Comunidade de Patrimônio da Penha. Assim, o PDM de Divino de São Lourenço vai estabelecer no Art. 114:

"É facultada a soma dos afastamentos laterais, em uma das divisas do lote, encostando a edificação na outra divisa, desde que nesta exista parede cega de uma edificação, com gabarito superior a três pavimentos». (PDM, p. 43, 2008)

A partir do mapa de gabarito (Mapa 5) foi possível analisar que as edificações não ultrapassam três pavimentos construídos e que há predominância de construções com apenas um pavimento. Os gráficos a seguir mostram esses quantitativos e porcentuais relativos a esse mapeamento.

\begin{tabular}{|c|c|}
\hline ZONEAMENTO & GABARITO \\
\hline Zona Residencial 1 - ZR 1 & 3 pavimentos \\
\hline Zona Residencial 1 - ZR 2 & 2 pavimentos \\
\hline Zona de Expansão Urbana - ZEU & 3 pavimentos \\
\hline Eixo Turístico - ET & 3 pavimentos \\
\hline
\end{tabular}




\section{MAPA DE GABARITO}

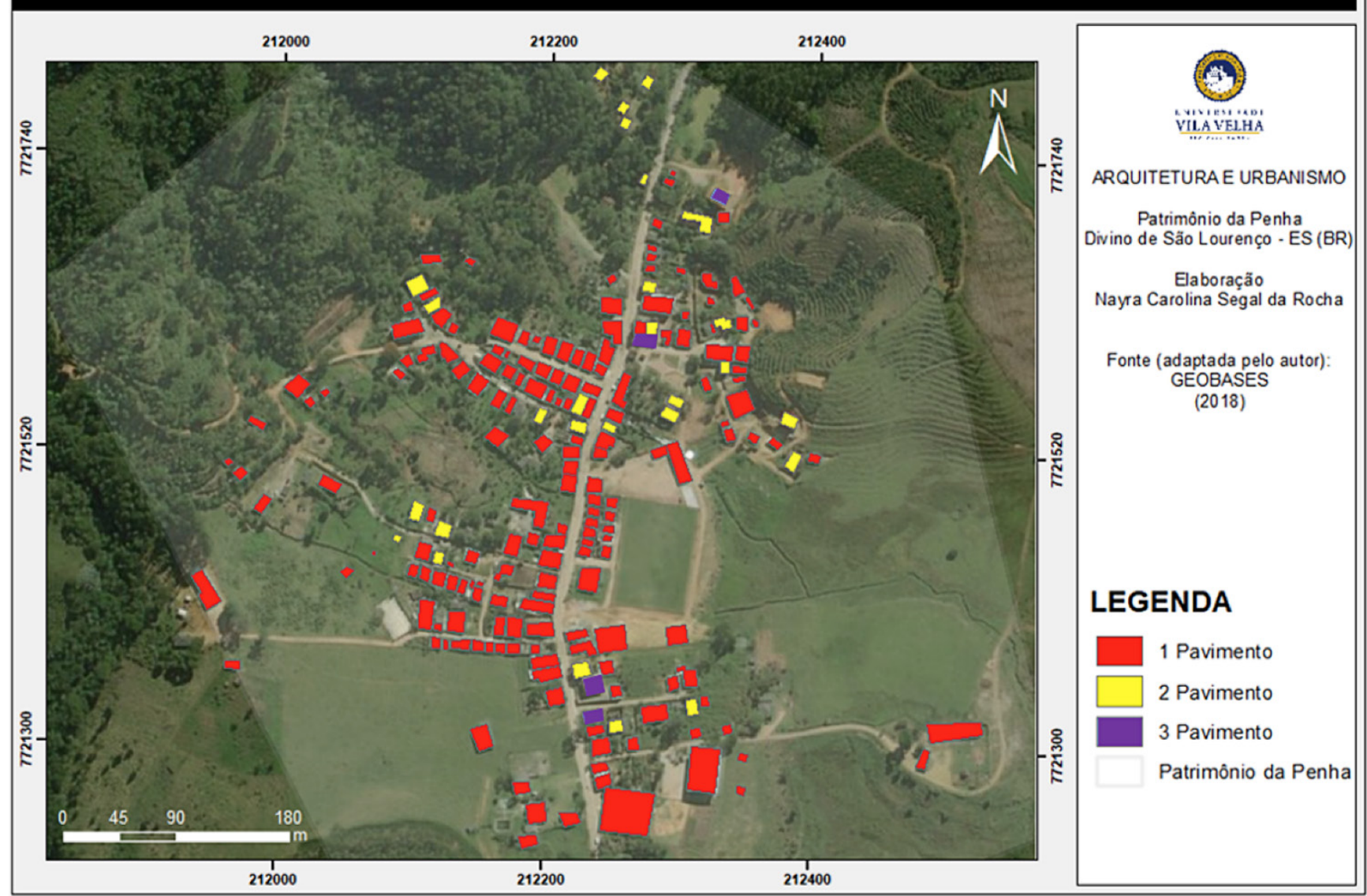

Mapa 5: Gabarito Construtivo de Patrimônio da Penha - ES. Fonte: Geobases (2018). Adaptado pelo autor e elaborador. 
Mapa 6: Tipologia viária por modelo de pavimentação. Patrimônio da Penha - ES. Fonte: Geobases (2018). Adaptado pelo autor e elaborador.

\section{Sistema Viário}

Para análise do mapa viário (Mapa 06) considerou-se a situação da pavimentação do local. Este levantamento é importante pra ajudar a compreender o desenho urbano estabelecido no território. Porém, por conta de se tratar de um núcleo em fase de desenvolvimento os limites ainda não estão bem definidos, isso ocorre em razão da diversidade métrica dos lotes e a maneira como as edificações se encontram inseridas dentro deste, o que somo a configuração do traçado irregular.

É importante também destacar a descontinuidade da malha viária, ao serem interrompidas é que as mesmas param nas proximidades de propriedades rurais e até mesmo em loteamentos particulares, temos ainda outro grande fator que influência na irregularidade da malha urbana.

Como forma de minimizar a configuração do desenho urbano é de interesse municipal que seja aplicado as legislações previstas no PDM municipal, além de estabelecer a reconfiguração da atual situação que se encontra a localidade que ainda carece de pavimentação e infraestrutura urbana para atender as novas demandas da Comunidade.

Sendo assim, devido à ausência de um plano urbanístico voltado a regularização dos loteamentos, não é possível analisar o perfil fundiário da Comunidade de Patrimônio da Penha, já que para isso é necessário a dimensão de cada lote.

\section{MAPA DE TIPOLOGIA DE VIAS}

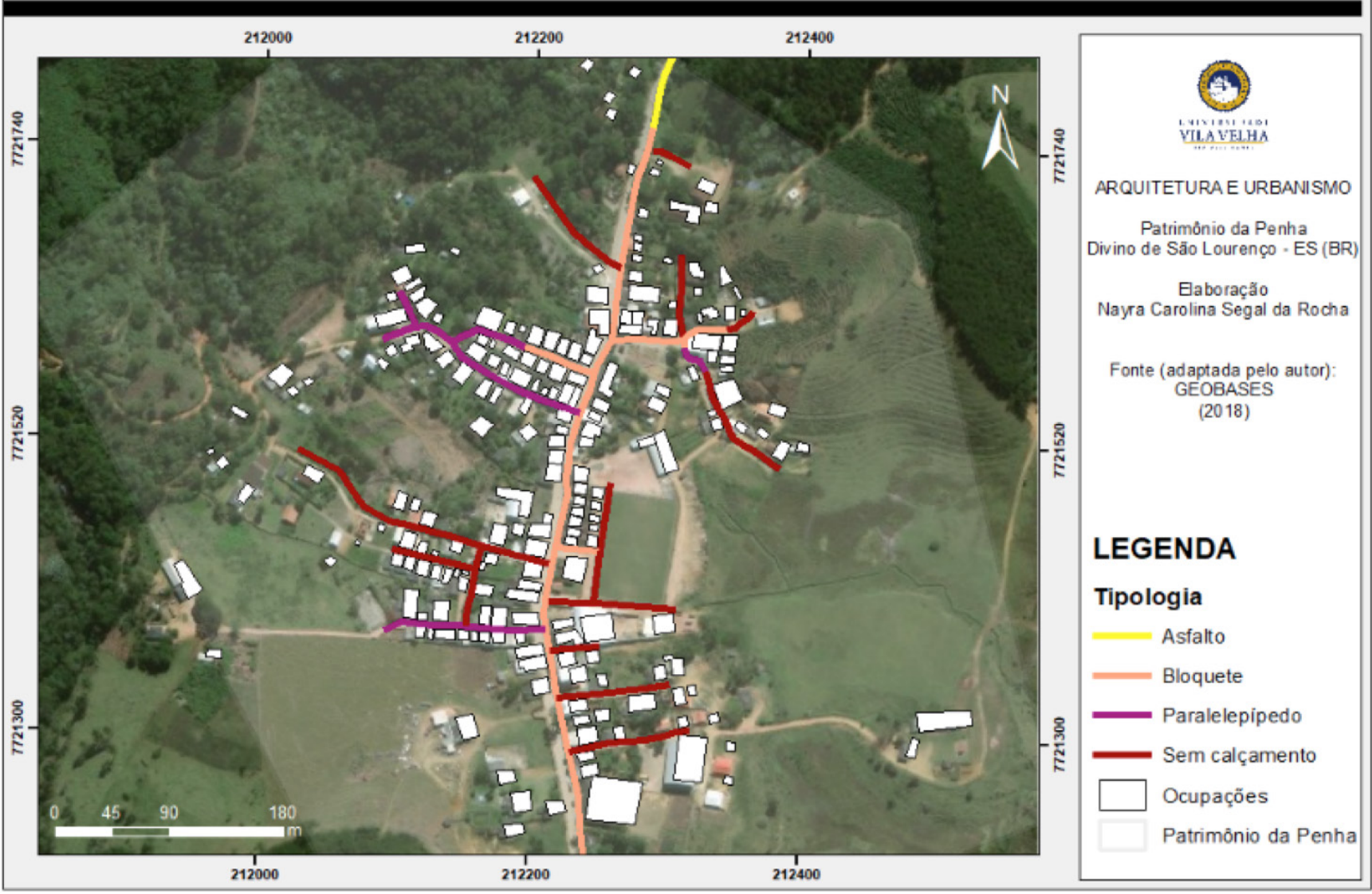




\section{Agenda urbana para Comunidade Patrimônio da Penha - ES}

Em 2016, uma conferência da ONU reuniu-se em Quito, capital do Equador, a fim de promover uma revisão de metas para o desenvolvimento global para os próximos anos, conhecida como "Nova Agenda Urbana" (NAU), que traçou objetivos que visassem o desenvolvimento urbano sustentável, "[...] esses documentos internacionais estabelecem objetivos e estratégias para o alcance do desenvolvimento sustentável nos níveis globais, nacional e subnacional" (GOMES, p. 03, 2018).

Além da promoção da sustentabilidade urbana, a agenda propõe, também, a ideia de "cidade para todos", que é expressa pela ONU como sendo:

(...) referente à fruição e ao uso igualitários de cidades e assentamentos humanos, almejando promover inclusão e assegurar que todos os habitantes, das gerações presentes e futuras, sem discriminações de qualquer ordem, possam habitar e produzir cidades e assentamentos humanos justos, seguros, saudáveis, acessíveis, resilientes e sustentáveis para fomentar prosperidade e qualidade de vida para todos (Nova Agenda Urbana, item 11). (BALBIM, p. 24, 2018)

A proposta da agenda urbana é apontar sugestões de modelo de sustentabilidade que possam vir a se adequar aos princípios da dinâmica local, tais como o respeito ao ambiente e à paisagem natural contemplada, levando em consideração a dimensão cultural da atuação dos atores sociais, como é o caso da Comunidade de Patrimônio da Penha.

De maneira geral, as diretrizes aqui propostas têm o intuito de se tornar um documento técnico para a gestão do território, de forma a salvaguardar as características singulares da região, ficando a critério dos órgãos fiscalizadores da gestão pública e o conselho local definir quais os pontos que devem ser levados em consideração no momento das intervenções urbanas dentro do espaço territorial.

\section{Conclusão}

Verifica-se que há uma ausência de diálogo entre as esferas públicas quanto a gestão das áreas de equilíbrio ambiental, tal como as Unidades de Conservação, principalmente o que tange as ocupações pré-existentes inseridas dentro do raio da zona de amortecimento de impacto.

É de interesse geral que haja um conselho de gestores que trabalhe em conjunto com as ações dos instrumentos de regulamentação ambiental, uma vez, que estes visam a garantia da instabilidade das áreas de preservação.

Esse estudo possibilitou refletir, também, a inserção humana no ambiente natural, dentro do território, e como seus usuários veem essa integração no futuro, buscando, para tanto, soluções práticas que possam contribuir, para a harmonia de ambos, na garantia de um ambiente saudável para as gerações futuras. Outra questão importante foi demonstrar de forma simplificada como funciona essa rede sistêmica da qual fazemos parte e que são extremamente importantes para a promoção da qualidade de vida. 


\section{Diretrizes para a preservação da paisagem natural}

\begin{tabular}{|c|c|}
\hline TEMA & DIRETRIZES \\
\hline MEIO AMBIENTE & $\begin{array}{l}\text { - Melhorar a qualidade do meio ambiente local } \\
\text { (saneamento básico, tratamento dos resíduos, } \\
\text { coleta seletiva etc.). } \\
\text { - Promover campanhas sobre a importância da } \\
\text { preservação do patrimônio natural existente; } \\
\text { - Determinar o tratamento adequado dos esgotos } \\
\text { domésticos, considerando os condicionantes da } \\
\text { região; }\end{array}$ \\
\hline LEGISLAÇÕES AMBIENTAIS & $\begin{array}{l}\text { - Cumprir a legislação ambiental de cunho mu- } \\
\text { nicipal e federal, além das normas técnicas (de } \\
\text { acordo com a localização do terreno e edifi- } \\
\text { cação). } \\
\text { - } \quad \text { Promover Políticas administrativas voltadas à } \\
\text { preservação ambiental; } \\
\text { Estabelecer um conselho de desenvolvimento } \\
\text { urbano ambiental definido a partir de estudos } \\
\text { ambientais, para que sejam identificadas as } \\
\text { áreas aptas ou não para ocupação. }\end{array}$ \\
\hline VEGETAÇÃO NATIVA & $\begin{array}{l}\text { - Preservar o máximo possível da vegetação } \\
\text { nativa e, assim, o ambiente natural. }\end{array}$ \\
\hline INTEGRAR ÁREAS VERDES & $\begin{array}{l}\text { - Promover a integração entre as áreas verdes } \\
\text { existentes e as áreas de lazer para os usuários. }\end{array}$ \\
\hline MINIMIZAR OS RISCOS & $\begin{array}{l}\text { - Conhecer e antecipar os possíveis riscos } \\
\text { ambientais. } \\
\text { - } \text { Reduzir os riscos de vulnerabilidade. } \\
\text { - Possuir um local adequado para o } \\
\text { armazenamento de matérias de combate a } \\
\text { qualquer possibilidade de risco. } \\
\text { Capacitar pessoas para lidar com situações de } \\
\text { risco }\end{array}$ \\
\hline CONE VISUAL & $\begin{array}{l}\text { - Delimitar os cones visuais que não impeçam a } \\
\text { visualização da cadeia montanhosa do Parque } \\
\text { Nacional do Caparaó. }\end{array}$ \\
\hline
\end{tabular}




\section{Diretrizes para uso do solo e gabarito}

\begin{tabular}{|c|c|}
\hline TEMA & DIRETRIZES \\
\hline $\begin{array}{c}\text { COMPATIBILIZAÇÃO } \\
\text { E INTEGRAÇÃO DO } \\
\text { PROJETO COM O } \\
\text { ENTORNO }\end{array}$ & $\begin{array}{l}\text { - Estimular a adequação do terreno às condições } \\
\text { topográficas. } \\
\text { - Em caso de movimentação de terra, que se tenha o } \\
\text { mínimo de impacto na morfologia do terreno. } \\
\text { Os terrenos que possuírem vegetação, que estas sofram } \\
\text { o mínimo de impacto possível. }\end{array}$ \\
\hline PERMEABILIDADE & $\begin{array}{l}\text { - Aumentar o percentual da taxa de permeabilidade } \\
\text { mínima nas Zona Residencial (ZR) e Zona de Expansão } \\
\text { Urbana (ZEU). } \\
\text { - Nos Eixos Turísticos (ET) elevar a taxa de permeabilidade. } \\
\text { - Utilizar taxa de ocupação máxima do terreno menor ou } \\
\text { igual a } 60 \% \text {. }\end{array}$ \\
\hline AFASTAMENTOS & $\begin{array}{l}\text { - Que as edificações obedeçam ao mínimo do } \\
\text { afastamento exigido pelo Plano Diretor Municipal. }\end{array}$ \\
\hline GABARITO & $\begin{array}{l}\text { - Proibir edificações que ultrapassem a marca de } 4 \\
\text { pavimentos ou } 12 \text { metros de altura. } \\
\text { Fiscalizar as alturas das edificações que estiverem dentro } \\
\text { do eixo visual voltado para cadeia montanhosa do Parque } \\
\text { Nacional do Caparaó. }\end{array}$ \\
\hline
\end{tabular}

\section{Diretrizes urbanas - Sistema viário}

\begin{tabular}{|c|c|}
\hline TEMA & DIRETRIZES \\
\hline PAVIMENTAÇÃO & $\begin{array}{l}\text { - Utilizar materiais porosos para a pavimentação externa. } \\
\text { - } \quad \text { Evitar a utilização de pavimentação asfáltica. } \\
\text { Buscar novas sugestões de materiais que possuam selo de } \\
\text { sustentabilidade. } \\
\text { - Aumentar a permeabilidade do sistema viário a partir da } \\
\text { utilização de materiais de pavimentação }\end{array}$ \\
\hline CALÇADAS & $\begin{array}{l}\text { - } \quad \text { Construir calçadas com largura mínima exigida pelo PDM. } \\
\text { - } \quad \text { Possuir acessibilidade plena na escolha dos materiais. } \\
\text { - } \quad \text { Aplicar piso de alerta tátil nas extremidades das calçadas } \\
\text { (quando necessário). }\end{array}$ \\
\hline CICLOVIAS & $\begin{array}{l}\text { - Vias compartilhadas que respeitem a mobilidade dos } \\
\text { ciclistas. } \\
\text { - Sinalizações que demostrem que há o compartilhamento } \\
\text { de vias. } \\
\text { - Estações de estacionamento de "bike". }\end{array}$ \\
\hline
\end{tabular}


Com isso, a partir dos resultados das diretrizes propostas para esta agenda urbana, é de interesse que outras localidades, que estejam passando por situações similares a de Patrimônio da Penha, possam usar este estudo como um instrumento para conduzir a elaboração das conformidades da gestão de suas ocupações urbanas nas proximidades das áreas de equilíbrio ambiental, de forma que estes - homem e meio natural - possam ter uma boa integração dentro do território, a fim de que as ações do homem não ultrapassem as possibilidades naturais do território.

\section{Referências bibliográficas}

BALBIM, Renato. "A nova agenda urbana e a geopolítica das cidades". In COSTA, Marco Aurélio; et al (ORG) A Nova Agenda Urbana e o Brasil: Insumos para sua construção e desafios a sua implementação. Brasília, 2018.

BRASIL. Instituto Chico Mendes de Biodiversidade. Brasília, 2018. Disponível em: <http://www. icmbio.gov.br/portal/component/content/article?id=2202:parna-de-caparao> Acesso em: 24 de julho de 2018.

DEL RIO, Vicente. Introdução ao desenho urbano no processo de planejamento. São Paulo. 1990.

DORNELAS, Henrique Lopes. O Direito Urbanístico e a importância do Plano Diretor Municipal. Revista do Curso de Direito - UNIABEU. Vol. $1 \mathrm{n}^{\circ} 1$. janeiro-julho. 2011.

FERREIRA, Gabriel Luis Bonora Vidrih; PASCUCHI, Priscila Mari. Zona de Amortecimento: A proteção ao entorno das unidades de conservação. In: Âmbito Jurídico, Rio Grande, XII, n. 63, abr 2009. Disponível em: <http://www.ambito-juridico.com.br/site/?n_link=revista_artigos_leitura\&artigo_id=5917>. Acesso em abr 2018.

GEHL, Jan; Cidade para pessoas. São Paulo, 2013.

GOMES. Joséli Fiorin. A "localização" dos objetivos de desenvolvimento sustentável e da nova agenda urbana da onu: a cooperação descentralizada sul-americana para implementar metas internacionais de urbanização sustentável. $4^{\circ}$ seminário de relações internacionais associação brasileira de relações internacionais (abri). Foz do Iguaçu. 2018.

LAMAS, José Manuel Ressano Garcia. Morfologia Urbana e Desenho da Cidade. Fundação Calouste Gulbenkian. 2007.

MASCARÓ, Juan Luis. Sustentabilidade em Urbanizações de Pequeno Porte. Porto Alegre, 2010. Infra-estrutura da Paisagem. Porto Alegre, 2008.

MASSINI, V.S. et al. O turismo em Patrimônio da Penha (ES) e suas interfaces com o Parque Nacional do Caparaó. Revista Brasileira de Ecoturismo, São Paulo, v.7, n.4, nov2014-jan2015, pp.715-734.

SANTOS, Elisângela Maria Barbosa. Parque Nacional do Caparaó: histórias de um lugar. Belo Horizonte, volume III, número 1, set 2013-fev 2014, p. 117-143.

SOUZA, Leandro Ricarte Castro de. Unidades de Conservação e conflitos socioambientais: Estudo de Caso dos conflitos pelo acesso e uso dos recursos naturais na zona de amortecimento de impacto do Parque Nacional do Caparaó - ES. Juiz de Fora. 2016.

TAVARES, Carlos A.P. O que são comunidades alternativas. Nova Cultura. São Paulo. 1985.

VILELA, Frederico Macedo; BOMFIM, Tuliane Machado. Gestão de Unidades de Conservação: Princípios e Ações para um Meio Ambiente Equilibrado. V Congresso Brasileiro de Gestão Ambiental. Belo Horizonte/ Minas Gerais, 2014. Disponivel em: <http://www.ibeas.org.br/ congresso/Trabalhos2014/NI-066.pdf> Acesso em: 19/06/2018. 